\title{
Effect of Intensive Endurance Training Program on Blood Hepcidin Levels: Relation to Iron Deficiency Anaemia in Long Distance Runners.
}

\section{Maha Khalil Mohamed}

Asst.Prof.of Biological science and sports health department, faculty of physical education for girls, Helwan University. Egypt.

\begin{abstract}
Athletes trained for regular intensive endurance exercise often have sports anaemia characterized by low blood iron and haemoglobin levels with decreased aerobic capacity, increases heart rate and elongates the recovery time after exercise. The antimicrobial hepcidin peptide secreted from liver found also to play an important role in iron metabolism leading to iron deficiency. Hepcidin secretion is induced by IL6 elevation after exercise in a case resembles acute phase. This study was proposed to investigate effect of hepcidin on blood iron due to chronic regular intensive program. Eight female athletes from the physical education field games team constituted subjects of this study. Their blood levels of hepcidin, IL6 and iron were measured pre, post and after 6 hours of exercise before and after the program. They were subjected to run on a treadmill at $75 \%$ of their VO2max for duration of 60 minutes/day for 5days/week for four weeks. Results revealed both acute and chronic low iron levels but only acute hepcidin and IL6. Theses results conclude that regular intensive training exercise leads to decreased blood iron causing sports anaemia. Also, iron is highly recommended to be supplemented during such periods in any sports program.
\end{abstract}

\section{Introduction}

$\mathrm{P}$ revious studies revealed that long-term regular exercises make positive contributions into human organism including physical, physiological, psychological and motor features (Auersperger et al., 2012). The most important effect of regular exercise is on blood hematology (Koç et al., 2010). More recent studies concerned the effect of regular exercise on hematology stated that these differences in results depend on the severity, duration and frequency of exercise as well as physical and physiological conditions of subjects (Büyükyazı and Turgay, 2000). Furthermore, the severity, duration and frequency of exercise should be wellorganized to have similar positive influence on blood (Baltac1 et al., 1998; Shephard and Shek, 1994). Athletes trained for regular intensive endurance exercise often have low blood haemoglobin levels. It may even be below the normal range (13 $\mathrm{g} / \mathrm{dl}$ in men and $12 \mathrm{~g} / \mathrm{dl}$ in women) and associated with low haematocrit values giving rise to the concept of 'sports anaemia' with decreased aerobic capacity, increases heart rate and elongates the recovery time after exercise (Chatard et al., 1999).

Iron performs many important roles that are directly relevant to an athlete's performance. It plays a key role in a number of cellular processes such as DNA synthesis and electron transport. Furthermore, it is an essential component of haemoglobin, the oxygen carrying 
protein in the blood (Schumacher et al., 2002). Therefore iron depletion can affect physical performance. 5 6 It is not surprising that a significant loss of this metal commonly occurs with exercise. Early previous studies explained the mechanisms involved in exercise-induced iron loss are mainly gastrointestinal bleeding, haematuria, sweating and haemolysis5-7, with inflammation and hormone activity also being relevant, according to the more recent research in this field8. There is no evidence that iron supplementation increases athletic performance, except in individuals in whom iron deficiency is established (Ottomano and Franchini, 2012).

Hepcidin peptide secreted from liver was known to be an acute phase protein with antibacterial and anti fungal properties (Hunter et al., 2002). Recently, it is discovered that hepcidin play an important role in iron metabolism, was suggested by the observation that mice with disruption of the gene encoding the transcription factor failed to produce hepcidin mRNA and developed spontaneous visceral iron overload with consequent severe iron deficiency anaemia (Nicolas et al., 2002 A).

Hepcidin protein is a small cysteine-rich peptide hormone produced in the liver, circulated in blood in two forms designated as 20 and 25 amino acids peptides. Only hepcidin 25 is the active human form (Young et al., 2009). Hepcidin contains very high percentage of cysteines (eight cysteines in both the 20- and 25-residue peptide). This is an unusually high amount of Cys residues may compromise for its antibacterial activities. Hepcidin is believed to affect iron metabolism by decreasing iron absorption in the gut, iron recycling from macrophages, and control hepatic iron storage (Nemeth and Ganz , 2006). In the enterocyte, hepcidin binds to the basolateral iron export protein, ferroportin, initiating its internalization and degradation, effectively blocking iron flux from the cell and reducing iron absorption (Nemeth et al., 2004).

It appears that the interlreukin-6 (IL-6hepcidin axis is critically important for sports anaemia developed by regular intensive endurance exercise. In humans, the hepcidin increase elicited by IL-6 infusion (which resembles that induced by intensive endurance exercise) is accompanied by a $30 \%$ decrease in serum iron and in transferrin saturation (Nemeth et al., 2004). The induction of hepcidin by IL-6 results in limitation of iron supply to the bone marrow and hence is considered a major contributor to the pathogenesis of sports anaemia. Because most of the iron in the transferring compartment is destined for the bone marrow, hypoferremia resulting from excess hepcidin diminishes the amount of iron available for hemoglobin synthesis and erythrocyte production (Ganz and Nemeth, 2006).

Although hepcidin expression was shown to be inversely associated with iron absorption and expression of iron transport proteins, to date a significant relation between hepcidin expression and iron absorption in humans has not been established. Also there is no previous studies investigated the chronic intensive exercise effects on developing iron deficiency anaemia. The purpose of this study was to investigate whether intensive endurance exercise program for field game players for one month will result in sports anaemia. Serum interleukin-6, hepcidin levels and iron status in field game players 
will be assayed and investigate if they can be used as predictors for ongoing sports anaemia.

\section{Material and Methods}

\section{Subjects}

8 female subjects of the faculty of physical education field games players were recruited for this study. Subjects were not currently taking any prescription medications or anti-inflammatory medications that can affect results. They were signing a written, informed consent form for participation.

\section{Program Design}

Subjects were required to run on a treadmill at $75 \%$ of their $\mathrm{VO} 2 \mathrm{max}$ for duration of 60 minutes/day for 5days/week for four weeks. Their blood samples were acquired at rest (pre-exercise), after exercise (post-exercise) and after 6 hours of recovery.

\section{Blood analysis}

Blood samples were collected into Vacutainer tubes using standard procedures via venipuncture of the antecubital vein. Serum was used for the measurement of serum iron, hepcidin and IL-6. Whole blood collected in a
Vacutainer serum tube was allowed to clot, and then centrifuged for 15 minutes at $3200 \mathrm{rpm}$. Serum were separated and then stored at $-20^{\circ} \mathrm{C}$ for later analyses. Commercially available ELISA kits were used for the measurement of hepcidin and IL-6 (Bio-source, USA). Serum iron was measured using the commercially available reagents (Serum Iron: Stanbio Laboratory, USA).

\section{Statistical analysis}

A computer statistical program SPSS version 17 was used to analyze obtained data. Descriptive statistics, including means, standard deviations and ranges, were calculated for all measures. $\mathrm{T}$ test analysis was used to determine significant findings, with significance accepted at $p \leq 0.05$. A one-way ANOVA with repeated measures was performed for all variables in which significant main effects were observed.

\section{Results}

Anthropometric data that may affect the results of the research as (age- weight, height and training age) are presented in table (1) and all values of the skewness lies between $( \pm 3)$ which achieved the equivalence of the subjects.

Table (1)

Anthropometric Data for subjects volunteered for this study

\begin{tabular}{|c|c|c|c|c|}
\hline Variable & Unit & Mean \pm SD & K & S \\
\hline Age & Year & $21 \pm 0.67$ & 0.223 & -0.341 \\
\hline Weight & Kg & $60.88 \pm 2.53$ & -0.492 & -0.448 \\
\hline Height & Cm & $166 \pm 3$ & -0.611 & 0.263 \\
\hline T. age & Year & $4 \pm 0.76$ & 0.319 & 0.782 \\
\hline
\end{tabular}

K: Kurtosis S: skewness

Obtained data revealed significant variations in the Hepcidin and IL6 levels before program but not in iron levels before the program in the three collected blood samples. After the program, all the three parameters revealed high significance $(p<0.01)$ in the three investigated samples (Table 2). 
(Table 2)

Comparison of concentrations (Means \pm SD) Pre, post and after 6 hours for Hepcidin, IL6 and iron by ANOVA

\begin{tabular}{|c|c|c|c|c|c|c|}
\hline \multicolumn{7}{|c|}{ Before program } \\
\hline & Pre-exercise & Post-exercise & 6 hrs. recovery & $\mathbf{F}$ & $\mathbf{p}$ & Sig. \\
\hline Hepcidin (nmol/l) & $1.03 \pm 0.23$ & $5.52 \pm 0.63$ & $3.12 \pm 0.53$ & 166.45 & 0.00 & $\mathbf{S}$ \\
\hline IL6 (ng/ml) & $1.54 \pm 0.47$ & $5.23 \pm 0.84$ & $1.70 \pm 0.55$ & 85.29 & 0.00 & $\mathbf{S}$ \\
\hline Iron $(\mu \mathrm{g} / \mathrm{l})$ & $83.37 \pm 6.99$ & $86.5 \pm 10.62$ & $78.62 \pm 5.63$ & 1.95 & 0.17 & NS \\
\hline \multicolumn{7}{|c|}{ After program } \\
\hline & Pre-exercise & Post-exercise & 6 hrs. recovery & $\mathbf{F}$ & $\mathbf{p}$ & Sig. \\
\hline Hepcidin & $0.99 \pm 0.25$ & $5.67 \pm 0.97$ & $3.51 \pm 0.51$ & 104.27 & 0.00 & $\mathbf{S}$ \\
\hline IL6 & $1.68 \pm 0.82$ & $5.01 \pm 0.34$ & $2.03 \pm 0.6$ & 69.84 & 0.00 & $\mathbf{S}$ \\
\hline Iron & $74.37 \pm 4.5$ & $76.37 \pm 4.1$ & $70.12 \pm 3.14$ & 5.21 & 0.01 & $\mathbf{S}$ \\
\hline
\end{tabular}

There was decreased blood iron levels after the program compared to that obtained before program in all samples $(\mathrm{p}<0.05)$ while no significant variation could be detected in hepcidin and IL6 levels (Table 3).

(Table 3)

Paired Samples T Test difference significance for Hepcidin, IL6 and iron parameters in pre-program compared to post-program

\begin{tabular}{|c|c|c|c|}
\hline \multicolumn{4}{|c|}{ pre-exercise } \\
\hline & $\mathbf{t}$ & $\mathbf{p}$ & significance \\
\hline Hepcidin & 0.33 & 0.75 & NS \\
\hline IL6 & -0.51 & 0.63 & NS \\
\hline Iron & 3.04 & 0.02 & $\mathbf{S}$ \\
\hline \multicolumn{4}{|c|}{ Post-exercise } \\
\hline & $\mathbf{t}$ & $\mathbf{p}$ & significance \\
\hline Hepcidin & -0.34 & 0.75 & NS \\
\hline IL6 & 0.56 & 0.59 & NS \\
\hline Iron & 2.71 & $\mathbf{0 . 0 3}$ & $\mathbf{S}$ \\
\hline \multicolumn{4}{|c|}{6 hours after recovery } \\
\hline & $\mathbf{t}$ & $\mathbf{p}$ & significance \\
\hline Hepcidin & -1.41 & 0.20 & NS \\
\hline IL6 & -1.18 & 0.27 & NS \\
\hline Iron & 3.61 & 0.01 & $\mathbf{S}$ \\
\hline
\end{tabular}

\section{Discussion}

The present study was proposed to study assays for blood hepcidin, IL6 and iron to determine the effects of intensive endurance program for four weeks undergone through for the following reasons; it is long time proved that such 
programs lead to what is commonly defined sports anaemia. Also, iron deficiency resulted after the heavy periods of intensive sports programs lead to improper training fate with unexpected low adaptations for athletes in general (Koçi et al., 2012).

The significant increase in post-exercise hepcidin that lasts for more 6 hours after the exercise suggests that hepcidin cause long time effect of iron unavailability although IL6 returns to become -more or less- around its basal levels during this periods of times. Also, there is no chronic effect of the program on either hepcidin or IL6 but that is true for iron levels.

Regulation of hepcidin synthesis follows two major mechanisms; either by iron and oxygen availability or by inflammatory response (Ganz and Nemeth, 2006). Exercise induces acute phase inflammation like case, which lead to increased circulating IL6 levels in blood. IL-6 but not IL-1 $\alpha$ or TNF- $\alpha$ induce hepcidin synthesis in human hepatocytes while antiIL-6 anti-inflammatory markers inhibit the induction of hepcidin mRNA in human primary hepatocytes (Nemeth et al., 2004; Nemeth et al., 2003; Nicolas et al., 2002 B $\&$ Pigeon et al., 2001). This may explain why hepcidin is acutely elevated after the exercise session.

Mechanism of action of hepcidin on iron follows three major pathways; reduces iron to its ferrous ( $\mathrm{Fe} 2+$ ) form (absorbable form of iron) can be carried on the iron transporter, divalent metal transporter 1 (DMT1), which moves iron across the cell membrane. Secondly, hepcidin directly reduce the expression of ferroprotein on cell membranes, and at last, it binds cell membrane ferroprotein, causes it to be internalized and degraded with the loss of ferroprotein from the cell membrane ablates cellular iron export (Frazer and Anderson, 2003; Frazer et al., 2002; McKie et al., 2000 \& Nemeth et al., 2004). Regular repeating exercise sessions as designed by the program cause regular elevation of hepcidin which lasts for about 6 hours and hence, lead to decreased bioavailability of iron with iron deficiency manifestation comprising subsequent sports anaemia.

\section{Conclusion}

Regular, intense physical activity is often associated with chronic low iron levels associated with temporally increased hepcidin levels with subsequent sports anaemia. Administration of iron supplements is highly recommended to avoid this iron anaemia. Also, post exercise hepcidin levels can be used as a novel predictor for subsequent anaemia may arise before competition and during high intensity periods of sports training. 


\section{Refernces}

1. Auersperger, I., Knap. B., Jerin, A., Blagus, R., Lainšček, M., Skitek, M., \& Škof, B. (2012): The effects of 8 weeks of endurance running on hepcidin concentrations, inflammatory parameters and iron status in female runners.

2. Int. j. sport nutr. exerc. metab, 22(1), 5563. PMid: 22248501

3. Baltacı AK, Moğulkoç R, Üstündağ B, Koç S, Özmerdivenli R (1998). A study on some hematological parameters and the levels of plasma proteins and serum zinc, calcium and phosphorus in young female athletes,

4. Gazi J. Phys. Educ. Sport Sci., 3(2): 21-28.

5. Büyükyazı G, Turgay F (2000). Acute and chronic effects of continuous and extensive interval running exercises on some hematological parameters,

6. Turk. J. Sport Med., 35(3): 103-113.

7. Chatard, JC.; Mujika, I.; Guy, C. and Lacour, JR. (1999): Anaemia and Iron Deficiency in Athletes: Practical Recommendations for Treatment

8. Sports Med 1999 Apr; 27 (4): 229-240

9. Frazer DM and Anderson GJ. (2003): The orchestration of body iron intake: how and where do enterocytes receive their cues?

10. Blood Cells Mol Dis 30: 288-297, 2003.

11. Frazer DM, Wilkins SJ, Becker EM, Vulpe CD, McKie AT, Trinder D, and Anderson GJ. (2002): Hepcidin expression inversely correlates with the expression of duodenal iron transporters and iron absorption in rats.
12. Gastroenterology 123: 835-844, 2002.

13. Ganz, T. and Nemeth, E. (2006): Hepcidin and regulation of body iron metabolism

14. Am J Physiol Gastrointest Liver Physiol 290: G199-G203, 2006;

15. Hunter, HN.; Fulton, DB.; Ganz, T. and Vogel, HJ. (2002): The Solution Structure of Human Hepcidin, a Peptide Hormone with Antimicrobial Activity That Is Involved in Iron Uptake and Hereditary Hemochromatosis

16. The Journal Of Biological Chemistry. 277, (40): 37597-37603, 2002

17. Koç H, Pulur A, Polat Y, Yardımcı M, Kaya M, Çoksevim, B (2010). The comparement of hematological symptoms of physical education and sports college's students. International Scientific Conference, Perspectives in Physical Education and Sport, Constanta, Romania, 21-23 May.

18. Koçi, H.; Tekin, A.; Öztürk, A.; Saraymen, R.; Gökdemir, K. and Eliöz, M. (2012): the effect of acute exercises on blood hematological parameters in handball players

19. African Journal of Microbiology Research Vol. 6(9), pp. 2027-2032, 2012

20. McKie AT, Marciani P, Rolfs A, Brennan K, Wehr K, Barrow D, Miret S, Bomford A, Peters TJ, Farzaneh F, Hediger MA, Hentze MW, and Simpson RJ. (2000): A novel duodenal iron-regulated transporter, IREG1, implicated in the basolateral transfer of iron to the circulation. Mol

21. Cell 5: 299-309, 2000. 
22. Nemeth E. and Ganz T. (2004): Regulation of iron metabolism by hepcidin.

23. Annu Rev Nutr 2006;26:323-42.

24. Nemeth E, Valore EV, Territo M, Schiller G, Lichtenstein A, and Ganz T. ( 2003): Hepcidin, a putative mediator of anemia of inflammation, is a type II acute-phase protein.

25. Blood 101: 2461-2463, 2003.

26. Nemeth E, Tuttle MS, Powelson J, Vaughn MB, Donovan A, Ward DM, Ganz T, and Kaplan J. (2004): Hepcidin regulates cellular iron efflux by binding to ferroportin and inducing its internalization.

27. Science 306: 2090- 2093, 2004.

28. Nicolas G, Bennoun M, Porteu A, Mativet S, Beaumont C, Grandchamp B, Sirito M, Sawadogo M, Kahn A, and Vaulont S. (2002 A): Severe iron deficiency anemia in transgenic mice expressing liver hepcidin.

29. Proc Natl Acad Sci USA 99: 4596-4601, 2002

30. Nicolas G, Chauvet C, Viatte L, Danan JL, Bigard X, Devaux I, Beaumont C, Kahn A, and Vaulont S. (2002 B): The gene encoding the iron regulatory peptide hepcidin is regulated by anemia, hypoxia, and inflammation.

31. J Clin Invest 110: 1037-1044, 2002.

32. Ottomano, C. and Franchini, M. (2012): Sports anaemia: facts or fiction?

33. Blood Transfus 2012; 10: 252-4

34. Pigeon C, Ilyin G, Courselaud B, Leroyer P, Turlin B, Brissot $\mathbf{P}$, and Loreal $\mathbf{O}$.
(2001): A new mouse liver-specific gene, encoding a protein homologous to human antimicrobial peptide hepcidin, is overexpressed during iron overload.

35. J Biol Chem 276: 7811-7819, 2001.

36. Schumacher, Y O.; Schmid, A.; D König, $D$ and Berg. A (2002): Effects of exercise on soluble transferrin receptor and other variables of the iron status

37. Br J Sports Med 2002;36:195-200

38. Shephard R, Shek P (1994). Potential impact of physical activity and sport on the immune system - a brief review.

39. Br. J. Sport Med., 28(4): 247 - 255.

40. Young, MF.; Glahn, RP.; Ariza-Nieto, MA.; Inglis, JI.; Olbina, G.; Westerman, M. and O'Brien, KO. (2009): Serum hepcidin is significantly associated with iron absorption from food and supplemental sources in healthy young women

41. Am J Clin Nutr 2009; 89:533-8 
